$\mathrm{DE}$

M E D I C I N A

T R O P I C A L

$\mathrm{DE}$

S ÃO PAULO

JOURNAL OF THE SÃO PAULO INSTITUTE OF TROPICAL MEDICINE

${ }^{1}$ Universidade Federal de Alagoas,

Faculdade de Medicina, Arapiraca, Alagoas, Brazil

2Secretaria Estadual de Saúde do Distrito Federal, Brasília, Distrito Federal, Brazil

${ }^{3}$ Universidade Federal de Jataí, Faculdade de Medicina, Jataí, Goiás, Brazil

Correspondence to: Laurisson

Albuquerque da Costa

Universidade Federal de Alagoas,

Faculdade de Medicina, Av. Manoel

Severino Barbosa, Bom Sucesso, CEP

57309-005, Arapiraca, AL, Brazil

E-mail: laurisson.costa@arapiraca.ufal.br

Received: 16 July 2020

Accepted: 24 November 2020

\section{Dengue associated with severe cutaneous leukocytoclastic vasculitis and pericardial effusion: a case report}

\author{
Laurisson Albuquerque da Costa ${ }^{\circledR 1}$, Eduardo Feitosa Santos ${ }^{1}$, Erielly Maria \\ Bezerra Araújo Feitoza1, Miyuki Yamashita', Joyce Cabral Andrade ${ }^{\circledR 2}$, Pedro \\ Vinicius Leite de Sousa ${ }^{\left({ }^{3}\right.}$
}

\section{ABSTRACT}

Dengue is a viral disease, caused by an arbovirus of the genus Flavivirus. In Brazil, its incidence rate is high with a broad clinical spectrum. This report discusses a rare case of dengue associated with cutaneous leukocytoclastic vasculitis and pericardial effusion with eminence of cardiac tamponade in a previously healthy patient with no comorbidities. The serology for dengue was positive and the histopathological analysis of the cutaneous lesions confirmed the diagnosis of leukocytoclastic vasculitis. After receiving treatment, the patient's condition greatly improved.

KEYWORDS: Dengue. Cutaneous leukocytoclastic vasculitis. Pericardial effusion.

\section{INTRODUCTION}

Dengue is a disease of viral etiology, caused by an arbovirus of the genus Flavivirus ${ }^{1}$. Although this disease has a high incidence throughout Brazil, the highest incidence is found in the Midwest and Southeast regions of the country². During 2018 and 2019, the number of dengue cases in Brazil increased by 599.5\%, with 205,791 cases registered in August 2018 and 1,439,471 cases in the same period of $2019^{3}$, The average mortality coefficient between 2003 and 2019 was 3.05/100,000 inhabitants².

Furthermore, dengue has a broad clinical spectrum, varying from asymptomatic to severe symptoms, with fluid leakage, shock, hemorrhage and even organs failure ${ }^{4}$. Pruritic maculopapular circumferential extensive cutaneous rash on the face and trunk occurs more frequently, with a few rare cases of leukocytoclastic vasculitis described in the literature ${ }^{4,5}$. Cardiac manifestations, which are often benign, may also occur. More severe manifestations such as myocarditis and small pericardial effusions may also occur, however, they rarely manifest as cardiac tamponade ${ }^{6}$.

The evolution of dengue to pericardial effusion is also rare, especially when associated with leukocytoclastic vasculitis. A case of dengue fever in a previously healthy individual is described in this report, in association with two rare clinical manifestations: leukocytoclastic vasculitis and pericardial effusion, and impending cardiac tamponade.

\section{CASE REPORT}

A 24-year-old male with no previous comorbidities presented with diffuse myalgia, headaches, retro-orbital pain and fever. On the first day of symptoms, he sought medical attention at the Dr. Serafim de Carvalho Clinical Hospital, in Jatai 
city, Goias State, Brazil. After performing laboratory exams and receiving intravenous hydration, the patient was sent to home care.

On the fourth day, the patient developed a respiratorydependent chest pain despite having improved from the systemic symptoms and fever. He has also complained of a continuous abdominal pain. Edema of the lower limbs with purpuric lesions on the extremities appeared at this time (Figure 1).

The patient presented no signs or symptoms such as oral ulcers, other extremity cutaneous rashes, arthralgia, arthritis or visual acuity impairment. The laboratory blood count exam results revealed thrombocytopenia $\left(105,000 / \mathrm{mm}^{3}\right)$, which led to a possible dengue diagnosis. Within $48 \mathrm{~h}$ of hospital admission, the patient developed dyspnea and the emergence of a pericardial friction. A transthoracic echocardiography was performed, showing significant pericardial effusion, along with signs of cardiac tamponade.

The patient underwent pericardial drainage that removed $200 \mathrm{~mL}$ of a yellowish liquid. New laboratory exams indicated a worsening of the thrombocytopenia $\left(80,000 / \mathrm{mm}^{3}\right.$, urea $43 \mathrm{mg} / \mathrm{dL}$, creatinine $1.10 \mathrm{mg} / \mathrm{dL}$, a urinalysis showed no changes in urinary sediment, aspartate aminotransferase $97 \mathrm{U} / \mathrm{L}$, and alanine aminotransferase $69 \mathrm{U} / \mathrm{L}$.

A chest computerized tomography (CT) showed a diffuse ground-glass image and signs of pulmonary congestion (Figure 2). Empirically, antibiotic therapy with ceftriaxone and oxacillin was started for a possible bacterial infection along with prednisone $80 \mathrm{mg}(1 \mathrm{mg} / \mathrm{kg})$. In addition, blood cultures, antinuclear antibodies (ANA), antineutrophil cytoplasmic autoantibody (ANCA), CH100, serology for Epstein-Barr virus, cytomegalovirus, hepatitis B, $\mathrm{C}$, and HIV, as well as biopsy of the cutaneous lesions.
Forty-eight hours after the drain passage, the patient experienced clinical improvement, and clear pericardial fluid along with the pericardial drain were removed. The analysis of the pericardial fluid showed a citrus-yellow color fluid with exudative pattern, negative BAAR test , red cells $4,100 / \mathrm{mm}^{3}$, leukocytes $8,100 / \mathrm{mm}^{3}$ (lymphocytes $18 \%$, neutrophils $82 \%$ ), glucose $14 \mathrm{mg} / \mathrm{dL}$, amylase $19 \mathrm{U} / \mathrm{L}$, proteins $4.42 \mathrm{~g} / \mathrm{dL}$, in addition to negative bacterial cultures.

This treatment has also improved the patient's platelet count, attenuating symptoms 10 days after their onset. As the polymerase chain reaction (PCR) and the detection of the virus nonstructural protein 1 (NS1) were not available, $\operatorname{IgM}$ and $\operatorname{IgG}$ tests for dengue were performed by an immunochromatographic method on the seventh day. The results were non-reactive for both, IgM and IgG antibodies. Later, on the tenth day, the test was repeated and this time the results were positive for both, IgM and IgG.

The cutaneous histopathological analysis was compatible with leukocytoclastic vasculitis (Figure 3). Furthermore, ANA, ANCA, hepatitis B, C, HIV, blood cultures and the serum complement were normal. The serology for cytomegalovirus and Epstein-Barr was negative for IgM, but positive for IgG. Cutaneous lesions regressed and the patient was followed-up for six months by a nursing team (Figure 1).

\section{DISCUSSION}

We present a case of dengue fever associated with severe manifestations of leukocytoclastic vasculitis and cardiac tamponade that evolved favorably after supportive treatment and pericardial drainage.

Dengue is one of the most prevalent arbovirus infections in Brazil with an incidence of 690.4 cases per 100,000 inhabitants $^{3}$. Fever is the first manifestation, associated

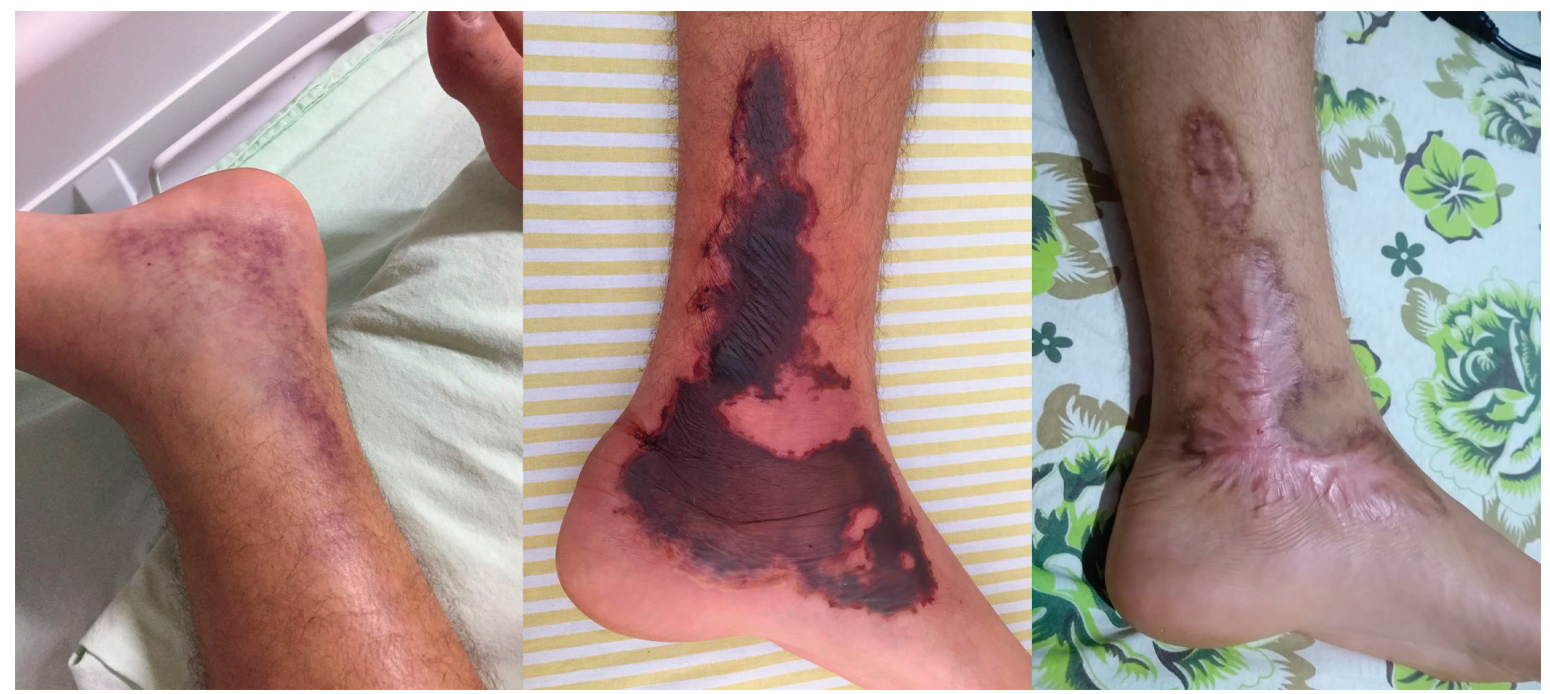

Figure 1 - Evolution of lesions on the extremities over 6 months. 


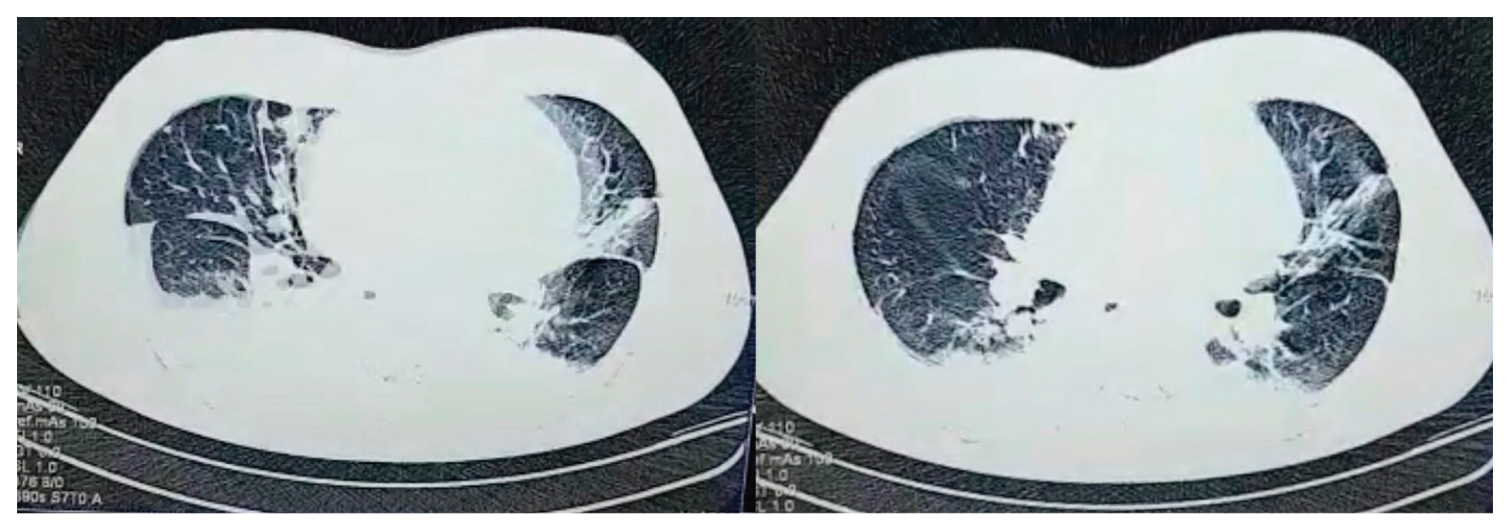

Figure 2 - The chest computerized tomography showing a diffuse ground-glass image and signs of pulmonary congestion.
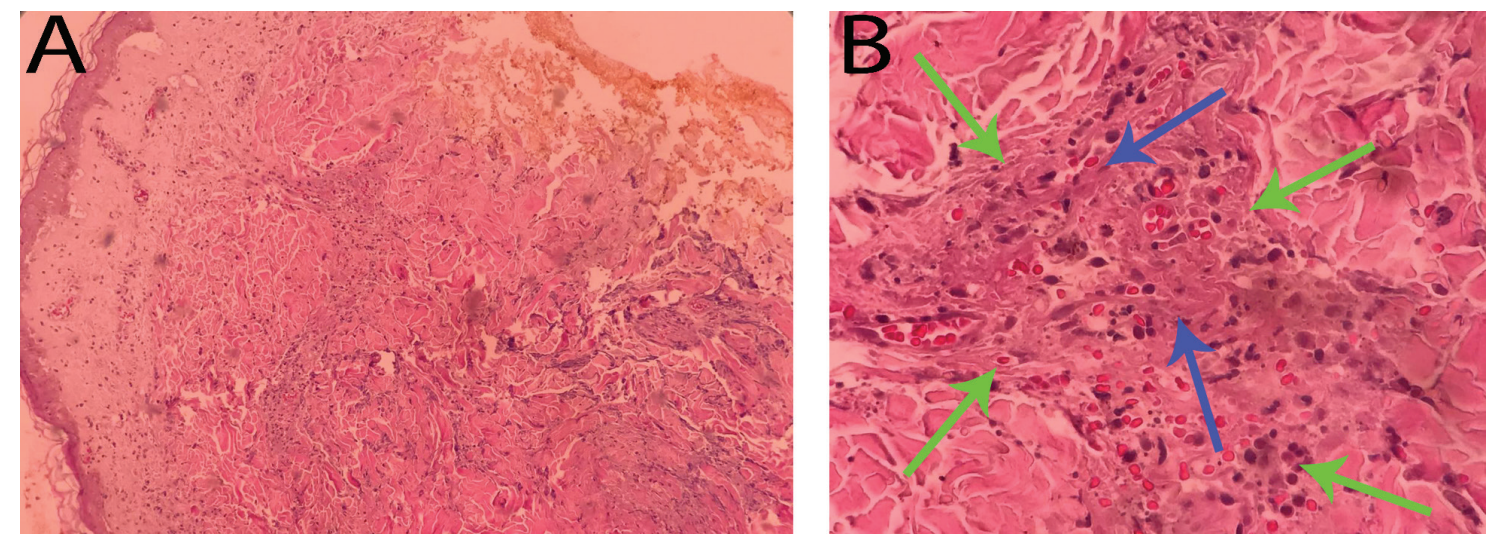

Figure 3 - Cutaneous leukocytoclastic vasculitis (hematoxylin-eosin, A 40 x and B $400 x$ magnification). The green arrows show perivascular neutrophilic infiltrates with nuclear dusts in the dermis, fibrin deposition on the vessel wall, congested vessels and extravasated red blood cells. In blue, fibrinoid necrosis.

with headache, retro-orbital pain and myalgia. Among the signs of alarm are intense and continuous abdominal pain, vomiting, fluid accumulation (ascites, pleural and pericardial effusion), hepatomegaly, postural hypotension and an increased hematocrit. Symptoms can progress to severe dengue with shock or accumulation of fluids, as well as respiratory distress, severe bleeding and signs of organ dysfunction ${ }^{1,4}$.

In our case, the patient manifested all aspects of the disease, expressing a concomitant panic regarding abdominal pain and cavitary effusions, evolving with dyspnea and cardiac tamponade and a positive serology for dengue on the tenth day. The patient's laboratory exams presented with negative results for ANCA and ANA, normal complement levels and urinalysis.

As for the physical examination, the patient presented with no other cutaneous rashes on the lower limbs, oral ulcers, arthritis or other clinical manifestations besides those already mentioned. Therefore, it was possible to rule out rheumatological diseases such as systemic lupus erythematosus, Behçet's disease and other vasculitis. Serology was also requested for Epstein-Barr and cytomegalovirus, hepatitis B, C and HIV, all of them with negative results. Tests for Zika virus were not performed since the patient presented none of the typical clinical manifestations such as macular or papular rash, puritus, non-purulent conjunctivitis or arthalgia ${ }^{7}$.

Leukocytoclastic vasculitis affects small vessels and can be caused by infections, such as HIV and hepatitis C, medications, systemic diseases such as malignancies and systemic lupus erythematosus, however, about $50 \%$ of the cases are idiopathic. The diagnosis was based on biopsy of the lesions ${ }^{8-10}$.

It should be noted, however, that leukocytoclastic vasculitis is a rare manifestation in dengue cases ${ }^{5}$. The interface between dengue and autoimmune diseases is described in the literature and may present a potential increased risk of autoimmune diseases such as systemic vasculitis development ${ }^{11,12}$. The mechanism for these events remains unclear with hypotheses varying from cross-reactivity with viral proteins, autoantibodies, up to the modulation of innate and adaptive immunities by the virus ${ }^{12}$.

Dengue can also act as a trigger for the onset of vasculitis in several ways, such as a direct cytopathic effect on the molecular mimicry of endothelial cells, release of cytokines and complement activation ${ }^{12,13}$. In the case 
presented, the association of dengue with leukocytoclastic vasculitis was due to several factors among them, signs and symptoms of dengue with serological confirmation, subsequent appearance of cutaneous lesions with diagnostic confirmation through cutaneous biopsy. As the patient was not taking any medication, other rheumatological and infectious diseases were ruled out.

As stated, another rare manifestation of the disease is cardiac tamponade. Although milder cardiac signs are commonly described in the literature, there are reports of more severe cardiac conditions ${ }^{6,14}$. However, to our knowledge, this is the first case involving two close clinical manifestations: leukocytoclastic vasculitis and pericardial effusion, with imminent cardiac tamponade.

As previously mentioned, this report is limited by the fact that polymerase chain reaction methods (PCR) and the detection of the virus nonstructural protein 1 (NS1) were not available for diagnosis, however, the patient presented with typical dengue symptoms and positive serological results on the tenth day.

\section{CONCLUSION}

It is well-known that dengue is a highly prevalent disease that can present with rare and serious manifestations. Thus, understanding the disease's manifestations can be crucial for the adequate diagnosis, treatment and management of the disease, as well as to ensure the best possible outcome for the patient.

\section{AUTHORS' CONTRIBUTIONS}

LAC: conceptualization, writing - original draft, review and editing, supervision, visualization; EFS: writing - original draft, review and editing, visualization; EMBAF: writing - original draft, review and editing, visualization; MY: writing - original draft, review and editing, supervision, visualization; JCA: writing - review and editing, supervision, visualization; PVLS: writing original draft, review and editing, supervision, visualization.

\section{CONFLICT OF INTERESTS}

All the authors declared no competing interests.

\section{FUNDING}

The authors received no specific financial support.

\section{INFORMED CONSENT}

A written signed consent form was obtained from the patient for this case report.

\section{REFERENCES}

1. Brasil. Ministério da Saúde. Dengue: aspectos epidemiológicos, diagnóstico e tratamento. Brasília: Fundação Nacional de Saúde; 2002.

2. Brasil. Ministério da Saúde. Secretaria de Vigilância em saúde. Vigilância em saúde no Brasil 2003/2019: da criação da Secretaria de Vigilância em Saúde aos dias atuais. Bol Epidemiol. 2019;N Esp:12-3.

3. Brasil. Ministério da Saúde. Secretaria de Vigilância em saúde. Monitoramento dos casos de arboviroses urbanas transmitidas pelo Aedes (dengue, chikungunya e Zika), semanas epidemiológicas 1 a 34. Bol Epidemiol. 2019;50:1-11.

4. Brasil. Ministério da Saúde. Secretaria de Vigilância em Saúde. Departamento de Vigilância das Doenças Transmissíveis. Dengue: diagnóstico e manejo clínico: adulto e criança. $5^{\text {a }}$ ed. Brasília: Ministério da Saúde; 2016.

5. Barraza M, Gómez R, Santacruz JG. Dengue y vasculitis leucocitoclástica. Univ Med. 2006;47:278-83.

6. Fernandes AI, Mendes CL, Simões RH, Silva AE, Madruga CB, Brito CA, et al. Cardiac tamponade in a patient with severe dengue fever. Rev Soc Bras Med Trop. 2017;50:701-5.

7. Brasil P, Calvet GA, Siqueira AM, Wakimoto M, Sequeira PC, Nobre A, et al. Zika virus outbreak in Rio de Janeiro, Brazil: clinical characterization, epidemiological and virological aspects. PLoS Negl Trop Dis. 2016;10:e0004636.

8. Baigrie D, Bansal P, Goyal A, Crane J. Leukocytoclastic vasculitis (hypersensitivity vasculitis). Treasure Island: StatPearls; 2020.

9. Koch M, Khan Z, Karle EM, Patel TP. Immune complex vasculitis: a rash that cannot be missed. BMJ Case Rep. 2020;13:e233545.

10. Lee HJ, Shin DH, Choi JS, Kim KH. Leukocytoclastic vasculitis associated with influenza A virus infection. J Korean Med Sci. 2012;27:1601-3.

11. Agarwal E, Shah D, Gupta P. Dengue fever triggering Kawasaki disease. Indian Pediatr. 2017;54:51-2.

12. Li HM, Huang YK, Su YC, Kao CH. Increased risk of autoimmune diseases in dengue patients: a population-based cohort study. J Infect. 2018;77:212-9.

13. Ghosh A, Banerjee A, Saha S, Pande A, Ghosh B. Wegener's granulomatosis with dengue fever: an unusual association. Int J Rheum Dis. 2012;15:e47-9.

14. Kumar S, Iuga A, Jean R. Cardiac tamponade in a patient with dengue fever and lupus nephritis: a case report. J Intensive Care Med. 2010;25:175-8. 